\title{
Styracaceae novas da Amazônia
}

\author{
Marlene Freitas da Silva (") \\ Instituto Nacional de Pesquisas \\ da Amazônia
}

\section{SINOPSE}

Com a descrição abaixo de Styrax cinerea e Styrax squamulosa, 6 espécies do gênero sáo até ago ra conhecidas apenas para a região amazônica. As outras antes descritas eram: $\mathbf{S}$. guianensis Aubl, S. sieberi Perk, S. bicolor Ducke e S. tessmannii do Peru Amazônico.

\section{INTRODUÇÃo}

O estudo das espécies amazônicas do gênero Styrax levou-nos a constatar nas coleções pertencentes ao Museu Goeldi (MG) e Instituto Nacional de Pesquisas da Amazônia (INPA), a ocorrência de algumas entidades botânicas com caracteres morfológicos externos diferentes das espécies já conhecidas para a região (Ducke, 1947: 26-27), e que, por essa razão, mereceram a criação de duas novas espécies por nós publicadas em nota prévia (Silva, 1971.

Considerando a presença de domácias (acarodomácias) na face dorsal das fôlhas, na junção da nervura mediana com as nervuras secundárias, as quais, segundo classificação de (Stace, 1965: 31), é do tipo marsupiforme, notamos que os autores (De Candolle, 1844: 244272; Seubert, 1837: 185-196), nenhuma referência fazem a respeito desta particularidade, nem mesmo (Hutchinson, 1959: 37), menciona a familia entre aquelas que a apresentam. No entanto, embora não citadas pelos autores, as espécies: S. argyrophyllum Perk., S. cordatus (R. \& P.) A. DC., S. socialis Macbr. (Pure); S. buchtienii Sleumer (Bolivia); S. pentlandianus Romy e S. pseudargyrophyllus Sleumer (Colômbia), apresentam esta característica. Assim sendo, registramos para a Amazônia duas espécies acarófilas.

A seguir damos as diagnoses das novas espécies propostas por nós :

\author{
Styrax cinerea Ml. $\vec{F}$. Silva, sp. nov. (fig. 1) \\ = S. cinerea M. F. Silva in Acta Amazônica, \\ 1(1) : 23 (1971). Nomen nudum
}

Arbor $21 \mathrm{~m}$ alta, $40 \mathrm{~cm}$ trunci diametro; rami ad extremitatem nigrescentes, dense lepidoti-pubescens, ferruginei; folia subcoriacea, oblongilanceolata, discolora, supra glabra, subtus cinereo-pubescentia, $7.5-9.5 \mathrm{~cm}$ longa et ad 4.8 lata, margine integra vix undulata, basi obtu$\mathrm{sa}$, apice acuminato; petiolus ad $10 \mathrm{~mm}$ longus, angulosus, supra canalicalatus, ferrugineo-pubescens; nervi supra vix notati, lutei, subtus prominentes; nervi laterales ad basin domatiis in parte inferiore laminae tentum ornati. Inflorescentia paniculata; paniculae laxiflorae; flores terminales vel subterminales, axillares, breve pedunculatae, ad $8 \mathrm{~cm}$ longae; rachis, bracteolae et calyces saturate lepidoti, pilis stellatis interdum ferrugineis. Flores albi, pedicello 2 - bracteolato, bracteolis linearibus erectis vel recurvis ad $3 \mathrm{~mm}$ longis; calyx $4-5 \mathrm{~mm}$ longus, $5 \mathrm{~mm}$ diametro ad marginem aliquantum laciniatus, laciniis brevibus apiculatis, extus lepidotus, intus glabrus; corolle $12 \mathrm{~mm}$ longa, extus lepidota; petala 5 , lanceolata, apice acuto, intus rubescentia ad marginem at apicem dense pilosa. Stamina 10, antheris oblongi-lanceolatis; filamenta tubi longitudine connata, apicem versus libera, ad basin antherarum pilosa; pilis hispidis nitidis; ovarium globosum ad apicem stipitatum, pubescens $3 \mathrm{~mm}$ longum (cum stipite), 3 - loculare, multiovulatum, stilo longo $9 \mathrm{~mm}$ metiente; stigmate subgloboso 3 -lobato. Fructus ignotus.

Árvore de $21 \mathrm{~m}$ de altura por $40 \mathrm{~cm}$ de diä metro de fuste; extremidades dos ramos escura, densamente escamoso-pubescente, ferrugínea. Fôlhas semi-coriáceas, oblongo-lanceoladas, discolores, glabras na face ventral, na dorsal cinereo-pubescentes, de $7.5-9.5 \mathrm{~cm}$ de compri.

(*) - Bolsista do Conselho Nacional de Pesquisas. 


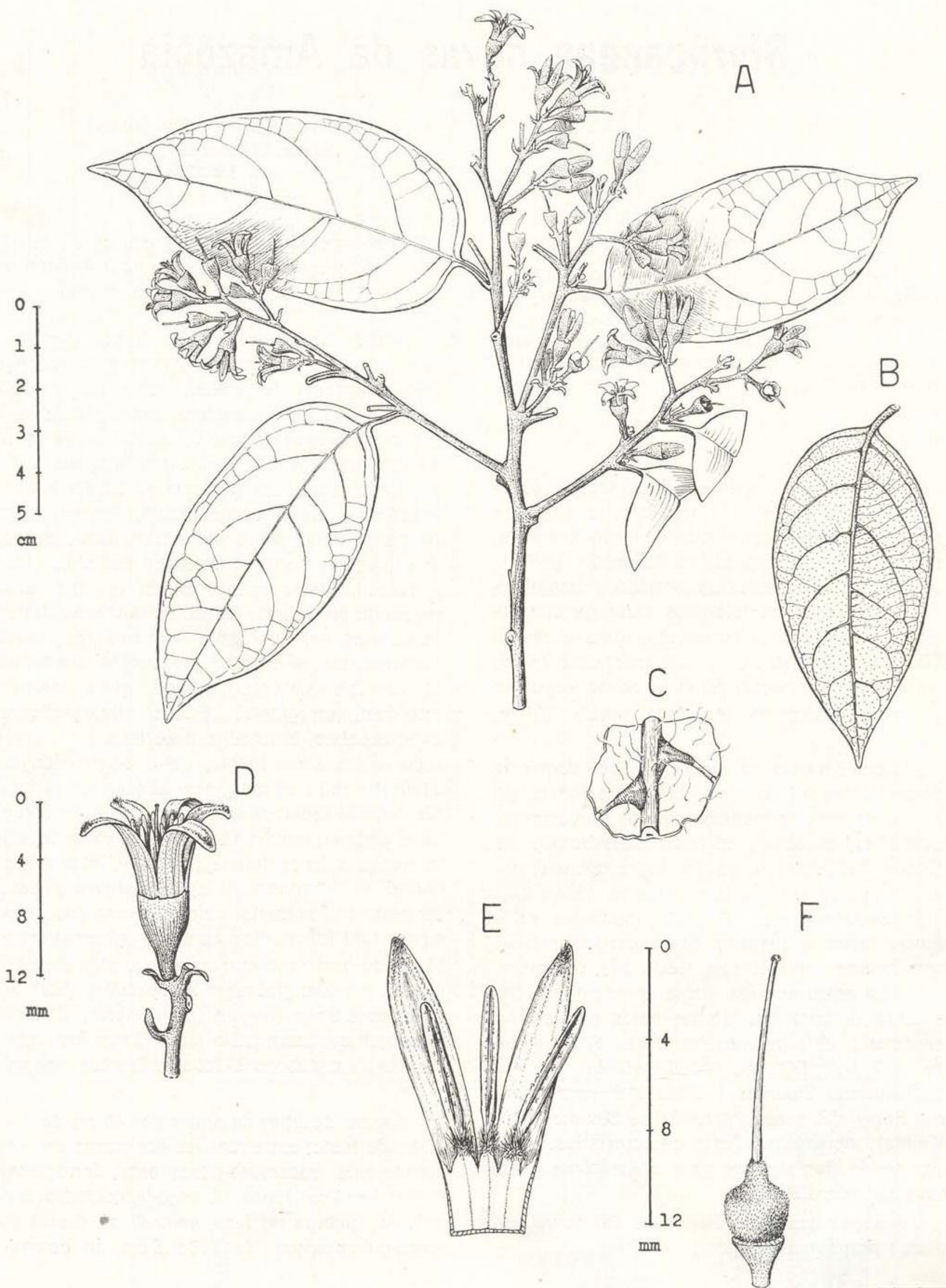

Fig. 1 - Styrax cinerea..M. F. Silva, n. sp. A-Hábito de um ramo fértil. $B$ - Fôlha. C - Detalhe das domácias. $D$ - Flor ampliada. $E-$ Detalhe da parte interna da corola. $F-$ Ovário estipitado. (Desenhos de J. Dellome Filho) 
mento, até $4-8 \mathrm{~cm}$ de largura, margem inteira, ligeiramente ondulada, base obtusa, ápice acuminado; pecíolo até $10 \mathrm{~mm}$ de comprimento anguloso, canaliculado na face superior, ferrugineo-pubescente; nervuras apenas visiveis na face superior, amarelas, no dorso proeminentes, com domácias no ponto de junção das nervuras secundárias com a nervura primária, até aproximadamente a metade do comprimento total da fôlha, raramente atingindo os $3 / 3$. Inflorescências em panículas laxifloras, curtas, terminais ou pseudo-terminais, axilares, com pedúnculo curto, até $8 \mathrm{~cm}$ de comprimento; ráquis, bractéolas, pedicelo e cálice densamente escamoso-pubescentes; pêlos estrelados, alguns ferrugíneos. Flôres brancas, pedicelo 2 -bracteolado; bractéolas lineares, eretas ou recurvadas, até $3 \mathrm{~mm}$ de comprimento; cálice de 4-5 $\mathrm{mm}$ de comprimento por $5 \mathrm{~mm}$ de diâmetro maior, com as bordas ligeiramente laciniadas, com apículos curtos, externamente escamosopubescente; pétalas 5 , lanceoladas, ápice agudo, internamente avermelhadas, com a margem e o ápice densamente pilosos Estames 10, com anteras oblongo-lanceoladas; filetes soldados até a altura do tubo, livres sòmente no ápice, densamente pilosos junto à base da antera; pêlos híspidos e brilhantes; ovário globoso, estipitado no ápice, pubescente, de $3 \mathrm{~mm}$ de comprimento incluindo o estípite, por $2.5 \mathrm{~mm}$ de diâmetro, 3-locular, multiovulado; estilete longo, $9 \mathrm{~mm}$ de comprimento, estígma subgloboso, 3 -lobado. Fruto desconhecido.

Habitat: Brasil, Amazonas, South Santo Antônio. Tree to 16 inches in diameter, 70 feet in height, common along slopes from mix forest. Flowers white, stamens and anthers yellow. Leaves green on top and gray beneath.

Holotypus: R. Boyan, 290, em 4.III.1968, in INPA 21.107.

Stryrax squamulosa M. F. Silva, n. sp. (fig. 2) $=S$. squamulosa M. F. Silva in Acta Amazônica, 1(1) : 23 (1971). Nomen nudum

Arbor ad $20 \mathrm{~m}$ alta $25 \mathrm{~cm}$ trunci diametro; rami juniores nigrescens, maculis albidis notati ad extremitate densiter escamosi. Folia lanceolata vel oblongi-lanceolata, membranacea, glaberrima ad $12 \mathrm{~cm}$ longa et $3-5.5 \mathrm{~cm}$ lata, subtus nitide, supra pallida, ad marginem integra, ad basin cuneata, apice atenuato vel breve acuminato; petiolus gracilis, $7-10 \mathrm{~mm}$ longus, dense escamosus, glaucescens; venuli reticulati subtus prominenteś; nervi lateralis ad basin domatiis in dimidio inferiore laminae tantum notatis; venae tertiariis numerosae utrinque notatae. Inflorescentiae paniculatae; paniculae terminalis vel pseudo-terminalis, vulgo $2-3$ in axilla foliorum aggregatae, pedunculo breve, ad $15 \mathrm{~mm}$ longae; rachis, pedicelus, bracteolae et calyx dense lepidoti, squamis luteolis. Inflorescentiae 1-7 florae; flores albi, ad basin 2 -bracteolati; bracteolis linearibus, racurvis vel erectis, usque ad $2 \mathrm{~mm}$ longis in aestivatione ad $2 \mathrm{~mm}$ longis, caducis; calyx cupuliformis vel campanulatus, $4-5 \mathrm{~mm}$ longus $5 \mathrm{~mm}$ diametro ad marginem vix laciniatus, intus dense lepidotus. Corolla $12-15 \mathrm{~mm}$ longa e basi $1-1.5 \mathrm{~mm}$ sursum densiter lepidota; tubus $0.5 \mathrm{~mm}$ longus, intus glabrus; petala linearia apice incurvati-cuculato, intus tomentosa. Stamina 10 , antheris lineari-lanceolatis $0.5 \mathrm{~mm}$ longis ad rimas pilis stellatis ornata; filamenta ad $0.5 \mathrm{~mm}$ connata apice penicillato (pilis hispidis); ovarium densiter pilis brevibus albescentibus vestitum $2 \mathrm{~mm}$ longum, $2 \mathrm{~mm}$ diametro, 3 -loculare; stilus elongatus $6 \mathrm{~mm} \mathrm{me}$ tiens, compressus; stigma trilobatum. Fructus ignotus.

Árvore de $20 \mathrm{~m}$ de altura por $25 \mathrm{~cm}$ de diâmetro de fuste; ramos jovens escuros, com manchas esbranquiçadas, densamente escamosos nas extremidades. Fôlhas lanceoladas ou oblongo-lanceoladas, membranáceas, glabérrimas, até $12 \mathrm{~cm}$ de comprimento por $3-5.5 \mathrm{~cm}$ de largura, brilhantes na face inferior, na superior opacas, margem inteira, base cuneada, ápice atenuado ou curto-caudado-acuminado; pecíolo delgado, 7-10 $\mathrm{mm}$ de comprimento, den. samente escamoso, amarelado-brancacento; rede de nervuras proeminentes na face inferior, com domácias no ponto de junção das nervuras secundárias com a nervura principal, somente até a metade inferior da fôlha; veias terciárias numerosas, aparentes em ambas as faces. Inflorescência em panículas terminais ou pseudo-terminais, freqüentemente $2-3 \mathrm{~cm}$ cada axila foliar, pedúnculo floral curto, até $15 \mathrm{~mm}$ de comprimento; ráquis, pedicelo. 

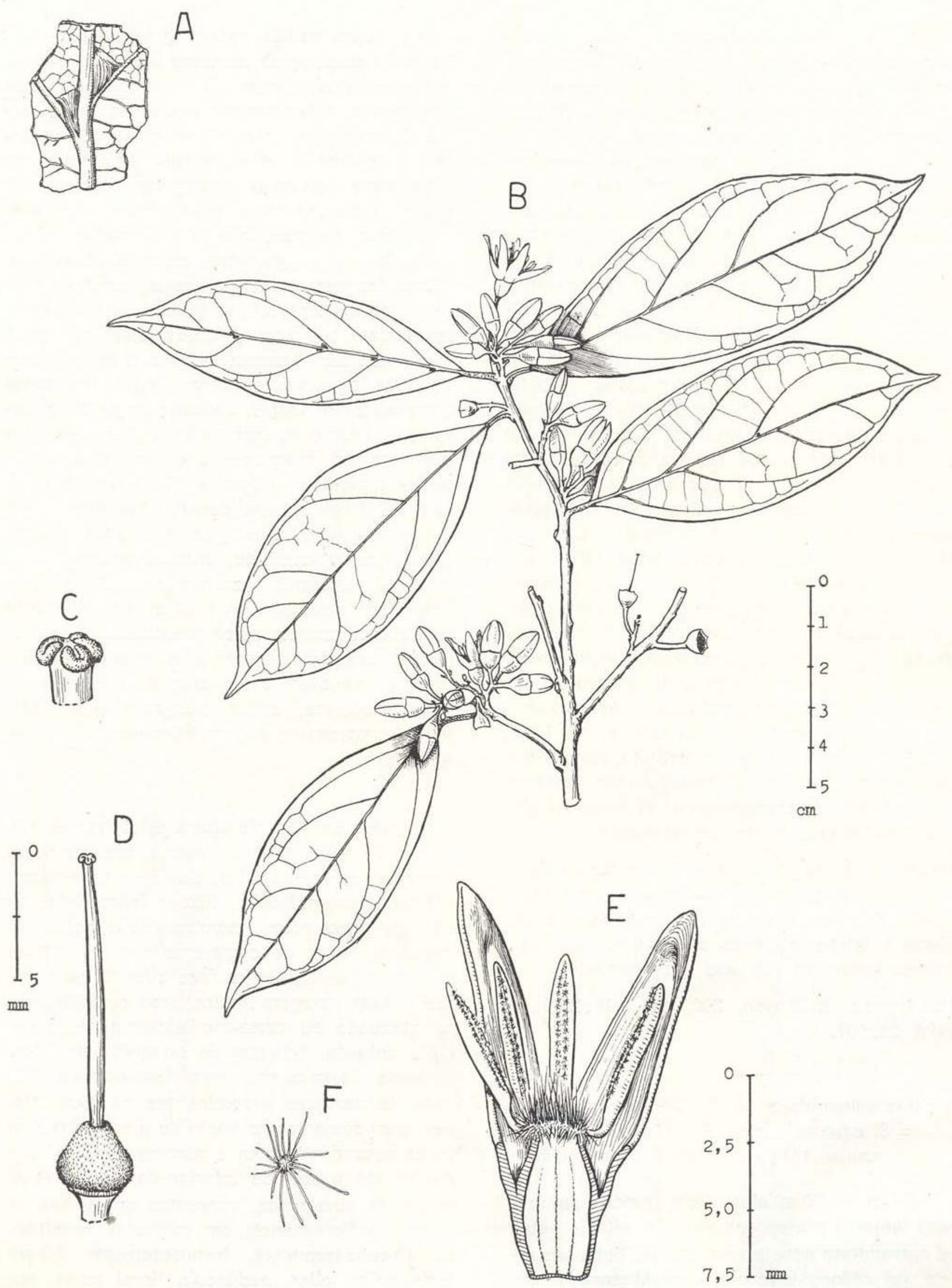

Fig 2 - Styrax squamulosa M. F. Silva, n. sp. $A$ - Domácias. $B$ - Hábito de um ramo floral. $C$ - Estígma. $D$ - Ovário. $E-$ Detalhe interno da corola. $F-$ Pêlo estrelado.
(Desenhos de J. Dellome Filho) 
bractéolas e cálice densamente recobertos de escamas brancacento-amareladas. Flôres brancas, 1-7 por inflorescência, 2 -bracteoladas na base; bractéolas lineares, recurvadas ou eretas, até $2 \mathrm{~mm}$ de comprimento, caducas na ântese; cálice cupuliformes ou campanulado, 4-5 $\mathrm{mm}$ de comprimento por $5 \mathrm{~mm}$ de diâmetro, com as bordas ligeiramente 5 -laciniadas, densamente escamoso externamente. Corola de 12-15 mm de comprimento, densamente lepido ta externamente, exceto a $1-1.5 \mathrm{~mm}$ da base; tubo de $0.5 \mathrm{~mm}$ de comprimento, inteiramente glabro; pétalas lineares, ápice incurvado cuculado, internamente tomentosas. Estames 10; anteras linear-lanceoladas de $0.5 \mathrm{~mm}$ de comprimento, com pêlos estrelados na extensão das rimas; filetes soldados até a altura do tubo da corola, com um tufo de pêlos híspidos no ápice; ovário densamente recoberto de pêlos curtos, brancacentos, de $2 \mathrm{~mm}$ de comprimento, aplanado, com estigma captado, 3-lobado. Fruto desconhecido.

Habitat: Brasil, Amazonas, Manaus, Reserva Florestal Ducke, árvore 1.390 do levantamento. Flôres brancas, pouco aromáticas; estames amarelos. Mata de t. firme, solo argiloso.

Holotypus: W. Rodrigues, D. Coêlho 8.342, em 14.IV.1967, in INPA 19.540.

As espécies acima descritas diferem entre si principalmente nas fôlhas, que em $S$. ci- nerea é discolor, na côr das flôres internamente e na forma do ovário, que em $S$. squamulosa não apresenta estípite.

\section{SUMMARY}

In this paper the author describer two new species acarofilous in the Styracaceae from Amazon Region - Styrax cinerea and S. squamulosa.

Among other characteristic feature, these species differ mainly from the other Amazonian species, in the membranaceous papillae on the dorsal surface of the leaves, which are found at the junction of the secondary nerves with the midrid outher lower $2 / 3$ of the leaves.

\section{BIBLIOGRAFIA CITADA}

De Candolle, A.

1844 - Prodromos Systematis Naturalis regnis vegetabilis. $8: 244$.

DUCKE, A.

1947 - New forest trees and climbers of the Amazon. Trop. Woods, $90: 26$.

HutChinson, J.

1959 - The familes of flowering plants. I - Dicotyledons. 2. ed. Oxford.

SEUBERT, M. 1837 - Martius flora brasiliensis. 7 : 185-96.

SiLvA, M. F.

1971 - Nota prévia sôbre Styracaceae novas na Amazônia. Acta Amazônica, Manaus, 1(1) : 23.

Stace, C. A.

1965 - Cuticular studies as an aid to plant taxonomy. Bull. Br. Mus, nat. Hist., London; Bot. 4(1). 